\title{
Tribocorrosion of Diamond-Like Carbon Deposited on Ti6Al4V
}

\author{
T. M. Manhabosco $\cdot$ I. L. Müller
}

Published online: 13 March 2009

(C) Springer Science+Business Media, LLC 2009

\section{Erratum to: Tribol Lett \\ DOI 10.1007/s11249-009-9408-8}

The fourth page, second paragraph of the original article includes some textual errors. The corrected text is as follows:

Figure 5 shows the wear track and counterbody profiles for blank Ti6Al4V (a) and DLC coatings (b) after wear and tribocorrosion tests. The wear volume at dry conditions for the bare alloy was about $1.35 \times 10^{-9} \mathrm{~m}^{3}$ while in tribocorrosion tests, the wear volume was $1.8 \times 10^{-9} \mathrm{~m}^{3}$ due the simultaneous action of corrosion and wear. As can be seen in Figure 5 (a), the presence of PBS solution changes the profile of wear track mainly on the bare alloy, when it becomes deeper and narrower than that from wear tests in air.

The online version of the original article can be found under doi:10.1007/s11249-009-9408-8.

T. M. Manhabosco $(\bowtie) \cdot$ I. L. Müller

Metallurgy Department, Laboratory of Corrosion Research,

Universidade Federal do Rio Grande do Sul, Av. Bento,

Gonçalves 9500/Setor 4/Prédio 75/232, 91501-970 Porto Alegre,

Rio Grande do Sul, Brazil

e-mail: tmanhabosco@yahoo.com.br 